\title{
Rehospitalization Prognostic Factors in Patients with Heart Failure: a Prospective Follow-up Study
}

\author{
Katerina Vitlianova1, "Mariya Negreva ${ }^{2}$ \\ ${ }^{1}$ Associate Professor, MD, PhD, DSc, Clinic of Cardiology -II City Hospital -Sofia, Bulgaria \\ Address for correspondence: Bulgaria, 120 Hristo Botev blv. \\ ${ }^{2}$ Assistant Professor, MD, PhD,First clinic of cardiology, University hospital "St. Marina", Varna, \\ Bulgaria Varna 9010, Hr. Smirnenski 1 str. \\ ${ }^{1}$ k.vitlianova@abv.bg, ${ }^{2}$ mnegreva@abv.bg
}

\begin{abstract}
Aim: The aim of this study was to assess the risk and rate of rehospitalisation due to decompensation of chronic heart failure $(\mathrm{CHF})$ in relation to certain biologic, clinical and instrumental characteristics.

Material and Methods: prospective study on 228 consecutive CHF patients. The follow-up period was 12 to 24 months. The primary endpoint was rehospitalization due to HF decompensation. The risk values were calculated using the Cox regression models.

Results: Median survival time was 8 months. The total number of rehospitalizations was 86 (37.7\%). Rehospitalization risk values were insignificantly lower in women (HR 0.7, 95\% CI 0.4-1.1, $p>0.05$ ) and higher in older age groups (HR $1.495 \%$ CI 0.8-2.2, p>0.05). Univariate regression analysis showed a higher rehospitalization risk in patients with survived myocardial infarction, clinical signs of $C H F$, high functional class and pulmonary pressure. Multivariate regression analyses revealed the leading role of functional class on rehospitalization risk.

Conclusion: rehospitalization rates due to decompensation of CHF are high. Age and gender are insignificant predictors for rehospitalization in our study. Functional class is the prognostic factor with an independent effect on rehospitalization risk over the defined follow-up period among the examined group of patients.
\end{abstract}

Keywords: heart failure, decompensation, rehospitalization, prognosis

Abbreviations: $C H F$ - chronic heart failure, $H F$ - heart failure, $L V E F$ - left ventricular ejection fraction, ECG - electrocardiography, NYHA - New York Hearth Association, FC - functional class, SAP - systolic arterial pressure, DAP - diastolic arterial pressure, ACE - angiotensin converting enzyme, ARBs - angiotensin receptor blockers, MI- myocardial infarction

\section{INTRODUCTION}

The prognosis of chronic heart failure (CHF) is determined by the complex relationship of neurohormonal, mechanical and polyorgan pathological changes emerging in the course and progression of the disease. Regardless of therapeutic advances in the treatment of CHF, prognosis is poor and mortality is high, comparable to that of most malignancies [1]. A considerable proportion of the health care cost is spent to cover repeated hospitalisations due to decompensation of CHF patients. According to data from different authors, the relative share of patients with CHF requiring rehospitalization within six months after discharge from hospital is approximately between 30 and $40 \%$ [2].

\section{MATERIAL AND MethodS}

The study was conducted on 228 consecutive patients with CHF, aged 23 to 94, with mean age of $67.6 \pm 11.59$ years. All patients were followed up for occurrences of complications for a period of 24 months. Complications during follow-up were defined as rehospitalization for decompensated CHF.

\subsection{Study Inclusion Criteria}

Patients were included according to the following criteria:

- Age over 18 years; 
- CHF was diagnosed in typical symptoms, radiological signs of pulmonary congestion, and/or significant clinical response to ongoing therapy. LVEF $>50 \%$ defines CHF with preserved left ventricular function (according to the American Heart Association and American College of Cardiology).

Ischemic heart disease (IHD) is defined in accordance with the established to date diagnostic criteria in patients with HF - presence of angiographic confirmation and/or a history of coronary heart attack and angina pectoris with respective clinical and electrocardiographic (ECG) characteristics [3].

\subsection{Study Exclusion Criteria}

The study did not include people with CHF caused by: primary pulmonary hypertension; congenital cardiovascular malformations; acute myocarditis; toxic cardiomyopathy; acute myocardial infarction or unstable angina pectoris within three months before the start of the study; cardiac surgery or invasive procedures in the past three months; symptomatic sinus node disease; A-V block II-III degree except patients with an installed permanent pacemaker; conducted cardio-pulmonary resuscitation within three months before the start of the study; severe motor or mental disabilities due to various reasons; neoplastic diseases;

Out of all 282 CHF patients, 54 were excluded due to the following reasons:

- did not agree to participate in the study (18 patients);

- did not meet the inclusion criteria (22 patients);

- not included due to a change in address, telephone or inability to contact them (14 patients).

All included patients were questioned and examined using a standardized protocol, including data from history and objective status. The duration of the interview and clinical examination was $60 \pm 30$ minutes and included questions about demographic and biological factors, and cardiovascular risk factors.

\section{The Studied Clinical Characteristics Included}

HF etiology (ischemic, non-ischemic), comorbidities, functional class (FC) according to NYHA (New York Hearth Association), heart rate, arrhythmias, presence of clinical signs of HF, undergoing therapy.

In order to define the individual follow-up period for each patient and reduce to the maximum the loss of patients during follow-up, the standardized protocol also included details of admission and discharge dates, as well as exact addresses and telephone numbers of included patients and/or their relatives.

The instrumental characteristics included:

- Standard ECG (12 leads)

- Radiographic study to assess presence of increased size of left heart chambers, pleural effusion, vascular stasis, cardiothoracic ratio $(<0.6 / \geq 0.6)$.

- Echocardiographic assessment of LVEF (\%) according to Simpson's formula in standard biventricular position or Teicholz in the absence of segmental LV disorders.

\subsection{Statistical Methods}

Quantitative indicators are presented as mean plus standard deviation (SD) and relative shares for qualitative variables. The differences between the categories of individual factors are realized by nonparametric analysis- calculation of chi-square for categorical variables and Student's t-test for quantitative variables.

Prognostic Analysis

The follow-up period was determined by hospital discharge date and the date of the occurrence of rehospitalization or discontinuation of the follow-up for the participants without complications.

Cox-Mantel test: comparative analysis of the prognostic effect of the different categories of studied factors.

Calculation of single- and multifactor risk values of complications during the follow-up period of individual factors was performed using univariate and multivariate Cox regression analysis.

Values of $\mathrm{p}<0.05$ were considered as statistically significant. Study data were analyzed using the statistical package SPSS 13.0. 


\section{RESULTS}

The median survival of the monitored by us patients was 8 months (range $0-24$ months). The total number of patients with registered hospitalizations until the end of follow-up period was $86(37.7 \%)$, with the highest rate until the 6th month from dehospitalization (28.9\%) (Table 1).

Table1. Rehospitalizations depending on follow-up period in months

\begin{tabular}{|l|l|l|}
\hline Follow-up period & Number of rehospitalizations & $\%$ \\
\hline 1 month & 35 & 15.4 \\
\hline 6 months & 31 & 13.5 \\
\hline 12 to 24 months & 20 & 8.7 \\
\hline Total & 86 & 37.7 \\
\hline
\end{tabular}

Rehospitalizations by Gender and Age

The duration of the period without rehospitalization is insignificantly longer in females (14.2 months) compared to males (11.1 months). Rehospitalization risk values (risk 0.7, 95\% CI 0.4-1.1, p>0.05) were insignificantly lower for women and higher in patients of older age groups (risk 1.4, 95\% CI 0.8 $2.2, \mathrm{p}>0.05)$.

\section{Prognostic Factors for Rehospitalization}

The comparative analysis of the frequency distribution of the characteristics of studied factors by group, depending on registration of rehospitalization during the follow-up are presented in Table 2 and 3 .

Patients with registered rehospitalization during the follow-up differed significantly from those without complications in the following factors: functional class (FC), diastolic blood pressure (DBP), peripheral stasis, radiological signs of pulmonary stasis, myocardial infarction (MI), therapy with angiotensin converting enzyme (ACE) inhibitors/ angiotensin receptor blockers (ARBs) and $\beta$ blockers, and CHF duration.

Table2. Demographic, clinical and therapeutic prognostic factors in CHF patients with CHF

\begin{tabular}{|c|c|c|c|}
\hline Indicator & & status & \\
\hline & $\begin{array}{l}\text { without complications } \\
(\mathrm{n}=142)\end{array}$ & $\begin{array}{l}\text { rehospitalization } \\
(\mathrm{n}=86)\end{array}$ & $\mathrm{P}$ \\
\hline Age $\geq 65$ years & $53.5(76)$ & $66.3(57)$ & 0.058 \\
\hline Women & $52.1(74)$ & $51.2(44)$ & NS \\
\hline Hypertension & $84.5(120)$ & $86.0(74)$ & NS \\
\hline Diabetes mellitus & $22.5(32)$ & $19.8(17)$ & NS \\
\hline Overweight $(\mathrm{BMI}>25 \mathrm{~kg} / \mathrm{cm} 2)$ & $72.2(78)$ & $64.6(42)$ & NS \\
\hline Dyslipidemia & $25.5(35)$ & $28.9(24)$ & NS \\
\hline HF duration $>3$ months & $62.0(88)$ & $81.4(70)$ & 0.002 \\
\hline Ischemic etiology of HF & $37.9(53)$ & $50.0(43)$ & NS \\
\hline Survived MI & $19.7(28)$ & $31.4(27)$ & 0.046 \\
\hline Clinical signs & & & \\
\hline Tachycardia ${ }^{1}$ & $19.0(27)$ & $16.3(14)$ & NS \\
\hline Atrial fibrillation (chronic) & $45.1(64)$ & $50.0(43)$ & NS \\
\hline $\mathrm{SAP}(\mathrm{mmHg})^{2}$ & $135.5 \pm 26.7$ & $127.4 \pm 22.8$ & 0.042 \\
\hline $\mathrm{DAP}(\mathrm{mmHg})^{2}$ & $84.0 \pm 17.1$ & $79.9 \pm 12.9$ & NS \\
\hline Functional class & & & \\
\hline I & $12.1(17)$ & $2.3(2)$ & NS \\
\hline II & $19.0(27)$ & $20.9(18)$ & NS \\
\hline III & $57.0(81)$ & $50.0(43)$ & NS \\
\hline IV & $12.0(17)$ & $26.7(23)$ & 0.007 \\
\hline Pulmonary stasis & $40.2(33)$ & $57.8(26)$ & 0.058 \\
\hline Peripheral stasis & $37.3(31)$ & $56.5(26)$ & 0.036 \\
\hline Therapy on admission & & & \\
\hline $\mathrm{ACE} / \mathrm{ARB}^{3}$ & $40.3(56)$ & $31.8(27)$ & NS \\
\hline$\beta$-блокер & $42.4(59)$ & $49.4(42)$ & NS \\
\hline Therapy on discharge & & & \\
\hline ACE/ARB & $59.0(82)$ & $63.5(54)$ & NS \\
\hline$\beta$-блокер & $64.7(90)$ & $71.8(61)$ & NS \\
\hline
\end{tabular}


$\overline{1}>100 \mathrm{BPM} ;{ }^{2}$ systolic/diastolic arterial pressure; ${ }^{3}$ angiotensin-converting enzyme ibitors/angiotensin receptor blockers; NS - statistically insignificant

Table3. Distribution by instrumental characteristics in CHF patients

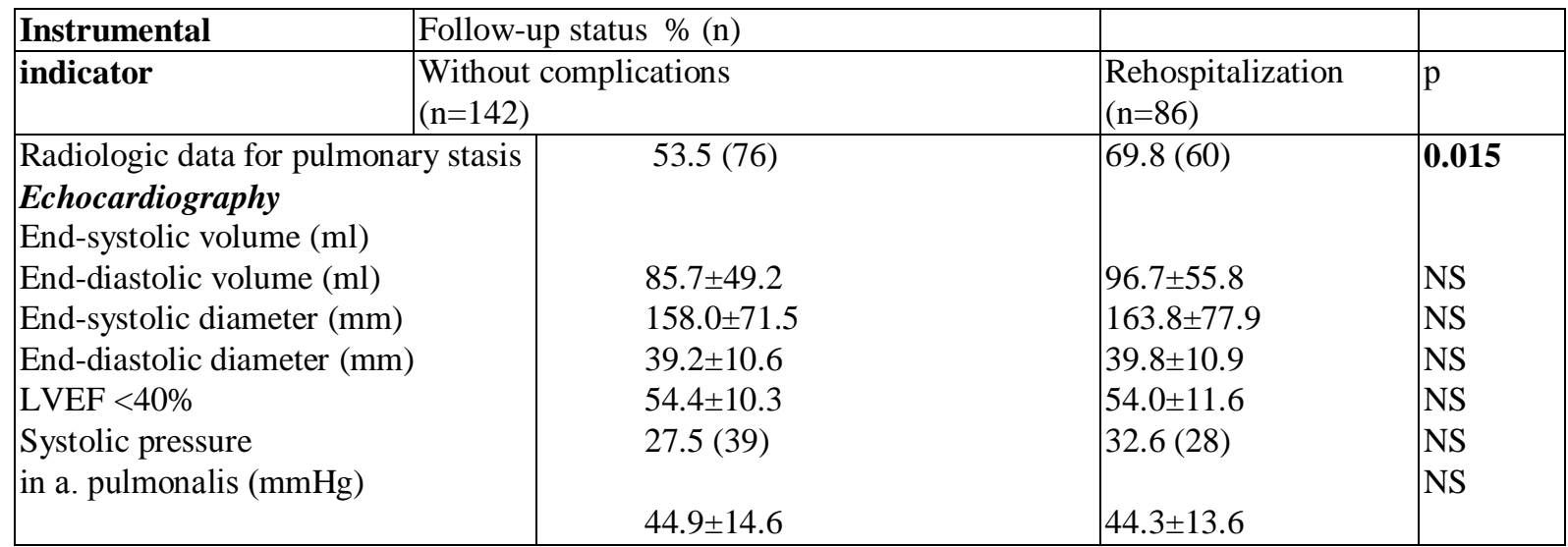

Univariate regression analysis results showed that patients who survived MI, clinical signs of CHF, high FC and indirect evidence of increased pulmonary pressure are with a high rehosptalization risk (Table 4).

Table4. Rehospitalization risk for the studied prognostic factors: uniariate Cox regression analysis

\begin{tabular}{|c|c|c|c|c|c|c|c|}
\hline Indicators & $\chi^{2}$ (Model) & $-2 \mathrm{LL}$ & $\boldsymbol{\beta}$ & SE & $\mathbf{H R}^{1}$ & $95 \% \mathrm{CI}^{2}$ & $\mathbf{P}$ \\
\hline Age $>65$ yeas & 2.1 & 770.4 & 0.33 & 0.2 & 1.4 & $0.8-2.2$ & NS \\
\hline Women & 2.1 & 770.4 & -0.32 & 0.2 & 0.7 & $0.4-1.1$ & NS \\
\hline Survived MI & 8.0 & 765.5 & 0.66 & 0.3 & 1.93 & $1.2-3.0$ & 0.005 \\
\hline $\begin{array}{l}\text { Clinical signs } \\
\text { DAP (mmHg) } \\
\text { Functional class }\end{array}$ & 2.8 & 365.8 & -0.02 & 0.01 & 0.97 & $0.9-1.0$ & 0.070 \\
\hline 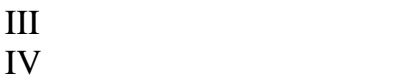 & 9.2 & 764.7 & $\begin{array}{l}0.09 \\
0.79\end{array}$ & $\begin{array}{l}0.2 \\
0.3\end{array}$ & $\begin{array}{l}1.10 \\
2.21\end{array}$ & $\begin{array}{l}0.6-1.8 \\
1.2-4.0\end{array}$ & $\begin{array}{l}\text { NS } \\
0.010\end{array}$ \\
\hline $\begin{array}{l}\text { Pulmonary stasis } \\
\text { peripheral edema }\end{array}$ & $\begin{array}{l}7.1 \\
6.5\end{array}$ & $\begin{array}{l}361.4 \\
371.6\end{array}$ & $\begin{array}{l}0.79 \\
0.08\end{array}$ & $\begin{array}{l}0.3 \\
0.3\end{array}$ & $\begin{array}{l}2.21 \\
2.1\end{array}$ & $\begin{array}{l}1.2-4.0 \\
1.1-3.9\end{array}$ & $\begin{array}{l}0.002 \\
0.012\end{array}$ \\
\hline $\begin{array}{l}\text { Radiological data for } \\
\text { pulmonary stasis } \\
\text { Systolic pressure } \\
\text { in a. pulmonalis (mmHg) }\end{array}$ & $\begin{array}{l}4.6 \\
0.54\end{array}$ & $\begin{array}{l}767.8 \\
512.3\end{array}$ & $\begin{array}{l}0.50 \\
0.009\end{array}$ & $\begin{array}{l}0.2 \\
0.009\end{array}$ & $\begin{array}{l}1.65 \\
1.007\end{array}$ & $\begin{array}{l}1.0-2.6 \\
1.03-1.08\end{array}$ & $\begin{array}{l}0.034 \\
0.000\end{array}$ \\
\hline $\begin{array}{l}\text { Therapy on discharge } \\
\text { ACE/ARB } \\
\beta \text {-blocker }\end{array}$ & $\begin{array}{l}4.50 \\
5.1 \\
\end{array}$ & $\begin{array}{l}756.6 \\
755.8\end{array}$ & $\begin{array}{l}0.49 \\
0.55 \\
\end{array}$ & $\begin{array}{l}0.2 \\
0.2 \\
\end{array}$ & $\begin{array}{l}1.63 \\
1.73 \\
\end{array}$ & $\begin{array}{l}1.0-2.5 \\
0.1-2.8 \\
\end{array}$ & $\begin{array}{l}0.035 \\
0.025 \\
\end{array}$ \\
\hline
\end{tabular}

${ }^{1}$ risk, ${ }^{2}$ confidence interval

Table5. Multi-factor regression model: clinical and instrumental indicators *

\begin{tabular}{|c|c|c|c|c|c|c|c|}
\hline Instrumental indicators & $\chi^{2}$ (model) & $-2 \mathbf{L L}$ & $\mathbf{B}$ & SE & HR & $95 \% \mathrm{CI}$ & $\mathbf{P}$ \\
\hline $\begin{array}{l}\text { Survived MI } \\
\text { Clinical signs } \\
\text { Atrrial fibrillation } \\
\text { Functional class } \\
\text { Pulmonary stasis } \\
\text { Peripheral stasis }\end{array}$ & 39.8 & 95.7 & $\begin{array}{l}0.55 \\
-0.03 \\
0.81 \\
0.89 \\
1.79\end{array}$ & $\begin{array}{l}0.56 \\
0.59 \\
0.41 \\
0.92 \\
0.91\end{array}$ & $\begin{array}{l}1.74 \\
\\
0.96 \\
2.25 \\
2.49 \\
6.02\end{array}$ & $\begin{array}{l}0.57-5.30 \\
0.3-3.0 \\
1.0-5.1 \\
0.4-15.1 \\
0.9-36.3\end{array}$ & $\begin{array}{l}\text { NS } \\
\text { NS } \\
\mathbf{0 . 0 5 0 N S} \\
\mathbf{0 . 0 5}\end{array}$ \\
\hline $\begin{array}{l}\text { Instrumental examinations } \\
\text { Radiological data for } \\
\text { pulmonary stasis } \\
\text { Echocardiography } \\
\text { LVEF }<40 \%\end{array}$ & & & $\begin{array}{l}0.69 \\
0.09 \\
\end{array}$ & $\begin{array}{l}0.74 \\
0.57 \\
\end{array}$ & $\begin{array}{l}1.99 \\
1.10 \\
\end{array}$ & $\begin{array}{l}0.4-8.6 \\
0.3-3.3\end{array}$ & $\begin{array}{l}\text { NS } \\
\text { NS }\end{array}$ \\
\hline
\end{tabular}

*after standartization by gender and age 
The complex nature of action of the individual prognostic factors with multiple blurring effects between them is reflected in the results of the multivariate regression analysis where the significance of a number of factors from the single-factor regression analysis disappears.

The inclusion of all factors in the model (Table. 5), after standardization of the role of gender and age, revealed the leading role of $\mathrm{FC}$ in determining the reospitalization risk for the studied group of patients.

\section{DisCUSSION}

Verdani et al. (2005) in a relatively recent study on 100 consecutive patients observed $17 \%$ rehospitalizations on the $30^{\text {th }}$ day, compared to $15.3 \%$ in our study. The results we obtained for the rehospitalization risk in patients with $\mathrm{CHF}$ is comparable both to the results published by Verdani, and data from previous studies on rehospitalization risk in connection with decompensated CHF [4].

A study conducted in Spain in 2005 on 204 patients established a higher rehospitalization rate than our data: $43 \%$ for 6 months follow-up, and patients with renal dysfunction and high FC had higher rehospitalization rates [5]. The higher rates can be explained by the higher mean age and higher proportion of comorbidities in the studied by Galofré et al. patients in Spain, in comparison to the characteristics of our study patients.

In the European Heart Failure Study (EHFS) of 8463 patients the rehospitalization rate in connection with decompensated HF was $20 \%$ of all hospitalizations for a 12 weeks follow-up, which corresponds to the established rehospitalization rate in our study. According to another large study conducted on 17,488 CHF patients, followed-up for six months, $44 \%$ were hospitalized at least once during the follow-up, and $18 \%$ of hospitalizations were in connection with CHF.

Repeated hospitalizations, a problem especially in elderly patients is partly associated with the observed high degree of comorbidity for these age groups. In this regard, for example, Vinson et al. studied prospectively 161 patients aged $\geq 70$ years. Hospital mortality amounted to $13 \%(\mathrm{n}=21)$. Approximately half of the discharged patients (47\%) were rehospitalized within three months after discharge. Approximately half of all hospitalizations were in connection with HF (38 patients, 57\%).

It is possible that the high relative share of patients aged $<65$ determined the lack of a significant effect of age in the formation of the rehospitalization risk in our study group. Studies that established a significant effect of age on rehospitalization risk are characterized by a significantly higher number of elderly patients. In a study by Vinson et al. independent rehospitalization predictors were: prior CHF, survived MI and uncontrolled hypertension, which corresponds to the established by us significant effect of MI in the univariate regression analysis. An important conclusion is that in $50 \%$ of cases in this study the rehospitalizations were preventable [2]. The effect of systolic pulmonary pressure could be due to the high comorbidity of a chronic obstructive pulmonary disease. This possibility is however unlikely, given the low percentage of patients who reported a chronic obstructive pulmonary disease $(28.4 \%, \mathrm{n}=64)$ of all studied patients. Furthermore, there is no data on differences in the incidence of this disease between the groups with and without rehospitalization ( $29.1 \%$ versus $27.5 \%$, respectively, $\mathrm{p}>0.05$ ).

Multivariate regression analysis in a study by Harlan et al. also shows an independent significant effect of rehospitalization for males (risk [OR], 1.12; 95\% CI 1.05-1.20), previous hospitalization (risk 1.64; 95\% CI, 1.53-1.77) and comorbidity, summarized and analyzed as comorbid sum (risk 1.56; 95\% CI 1.45-1.68). Age, similarly to our data, was an insignificant rehospitalization factor [6].

It is worth to note the lack of significant effect of systolic dysfunction on the hospitalization risk, one of the most frequently quoted prognostic factors. Similar to our results regarding the effect of this factor, Badano et al. Analyzed and followed-up for 6 months 179 consecutively hospitalized patients and did not establish differences in clinical symptoms, rehospitalization rate and fatal events among patients with systolic and diastolic dysfunction [3, 7]. 


\section{CONCLUSION}

Rehospitalization rates for decompensated CHF are high, the highest rate occurring during the first six months of follow-up. Age is a statistically insignificant predictor of rehospitalization risk. Women have an insignificantly better prognosis than men. Functional class was a prognostic factor with an established independent and significant prognostic effect on the rehospitalization risk for the defined followed-up period in the patients examined by us. The results are relevant to risk stratification and clinical approach in CHF patients.

\section{REFERENCES}

[1] Koelling TM, Chen RS, Lubwama RN, L'Italien GJ, Eagle KA. The expanding national burden of heart failure in the United States: the influence of heart failure in women. Am Heart J. 2004; 147(1):74-78.

[2] Vinson JM, Rich MW, Sperry JC, Shah AS, McNamara T. Early readmission of elderly patients with congestive heart failure. J Am Geriatr Soc. 1990; 38(12):1290-1295.

[3] Badano LP, Albanese MC, De Biaggio P, Rozbowsky P, Miani D, Fresco C, Fioretti PM. Prevalence, clinical characteristics, quality of life, and prognosis of patients with congestive heart failure and isolated left ventricular diastolic dysfunction. J Am Soc Echocardiogr. 2004; 17(3):253-261.

[4] Verdiani V, Nozzoli C, Bacci F, Cecchin A, Rutili MS, Paladini S, Olivotto I. Pre-discharge Btype natriuretic peptide predicts early recurrence of decompensated heart failure in patients admitted to a general medical unit. Eur J Heart Fail. 2005; 7(4):566-571.

[5] Galofré N, San Vicente L, González JA, Planas F, Vila J, Grau J. Predictive factors for readmission in heart failure patients. Med Clin (Barc). 2005; 124(8):285-290.

[6] Krumholz HM, Parent EM, Tu N, Vaccarino V, Wang Y, Radford MJ, Hennen J. Readmission after hospitalization for congestive heart failure among Medicare beneficiaries. Arch Intern Med. 1997; 157(1):99-104.

[7] Jones RC, Francis GS, Lauer MS. Predictors of mortality in patients with heart failure and preserved systolic function in the Digitalis Investigation Group trial. J Am Coll Cardiol. 2004; 44(5):1025-1029. 